\title{
Influence that Service in a Pro Bono Clinic has on a First Full-Time Physical Therapy Clinical Education Experience
}

\author{
Daria Porretta \\ Widener University - Main Campus, dcporretta@mail.widener.edu \\ Jill Black \\ Widener University - Main Campus, jdblack@mail.widener.edu \\ Kerstin Palombaro \\ Widener University - Main Campus, kpalombaro@mail.widener.edu \\ Ellen Erdman \\ Widener University - Main Campus, eaerdman@mail.widener.edu
}

Follow this and additional works at: https://nsuworks.nova.edu/ijahsp

Part of the Medicine and Health Sciences Commons

\section{Recommended Citation}

Porretta D, Black J, Palombaro K, Erdman E. Influence that Service in a Pro Bono Clinic has on a First FullTime Physical Therapy Clinical Education Experience. The Internet Journal of Allied Health Sciences and Practice. 2017 Jan 01;15(1), Article 11.

This Manuscript is brought to you for free and open access by the College of Health Care Sciences at NSUWorks. It has been accepted for inclusion in Internet Journal of Allied Health Sciences and Practice by an authorized editor of NSUWorks. For more information, please contact nsuworks@nova.edu. 


\title{
Influence that Service in a Pro Bono Clinic has on a First Full-Time Physical Therapy Clinical Education Experience
}

\begin{abstract}
Purpose: Physical therapist education programs strive to prepare their students for full-time clinical experiences in a variety of ways. Experiential and service learning in authentic contexts reportedly help students make connections between the classroom and the clinic. The purpose of this study was to explore the influences that service in a physical therapy pro bono clinic has on a first full-time clinical education experience.

Methods: Participants were all third year doctoral physical therapy students at Widener University who were entering their first full-time clinical education experience. Sixteen participants kept journals throughout their first full-time clinical experience regarding the impact of their previous pro bono experience. Upon completion of the 10-week full-time clinical experience, the sixteen participants answered a Likert-scale survey to further delineate the influence of the pro bono experience, and fifteen of the participants participated in focus group discussions to further explore themes that emerged from the journal and survey data. Data from the focus group and journals were analyzed qualitatively. The responses from the surveys provided quantitative data. In addition, the researchers looked at the Clinical Instructors (CI) midterm comments on the APTA's Clinical Performance Instrument (APTA PT CPI WEB) to further corroborate or disconfirm the findings.
\end{abstract}

Results: Triangulation of the data points revealed 9 categories of positive impact that the pro bono experience had on their first full-time clinical experience. The strongest three categories in order were client interaction, clinical instructor interaction, and professional communication. The next five categories were of relative equal strength and related to specifics areas of competency. They were competency in documentation, evaluation, intervention, clinical reasoning and cultural competency. A final overarching category was increased confidence. $\mathrm{Cl}$ comments on the midterm CPI corroborated these findings. Participants also shared ways in which the pro bono experience could have better prepared them for their full-time clinical experience.

Conclusions: Regular participation in a pro bono clinic throughout the didactic portion of the physical therapy curriculum contributed to student confidence and competence in their first full-time clinical experience. Future research should include interviews with the clinical instructors to further corroborate the student perceptions. The findings of this study also serve to inform how the pro bono clinical experience can be enhanced to further contribute positively to the students' first full-time clinical experiences.

\section{Author Bio(s)}

Dr. Daria Porretta, PT, DPT, conceptualized and designed the research study, refined survey questions, took notes in the focus groups and was responsible for qualitative analysis. Dr. Jill Black, PT, DPT, EdD, refined survey questions, led focus groups and was responsible for qualitative analysis. Dr. Kerstin Palombaro, PT, PhD, CAPS, was responsible for creating the survey and quantitative analysis. Dr. Ellen Erdman, PT, DPT, HPCS analyzed midterm clinical experience comments on the APTA PT CPIWEB instrument and refined survey questions. All authors were responsible for writing this article. 


\title{
TIJAHSP \\ The Internet Joutnal of Allied Health Sciences and Practice
}

Dedicated to allied health professional practice and education

Vol. 15 No. 1 ISSN 1540-580X

\section{Influence that Service in a Pro Bono Clinic has on a First Full-Time Physical Therapy Clinical Education Experience}

\author{
Daria C. Porretta, PT, DPT \\ Jill D. Black, PT, DPT, EdD \\ Kerstin M. Palombaro, PT, PhD, CAPS \\ Ellen A. Erdman, PT, DPT, HPCS \\ Widener University \\ United States
}

\begin{abstract}
Purpose: Physical therapist education programs strive to prepare their students for full-time clinical experiences in a variety of ways. Experiential and service learning in authentic contexts reportedly help students make connections between the classroom and the clinic. The purpose of this study was to explore the influences that service in a physical therapy pro bono clinic has on a first full-time clinical education experience. Methods: Participants were all third year doctoral physical therapy students at Widener University who were entering their first full-time clinical education experience. Sixteen participants kept journals throughout their first full-time clinical experience regarding the impact of their previous pro bono experience. Upon completion of the 10-week fulltime clinical experience, the sixteen participants answered a Likert-scale survey to further delineate the influence of the pro bono experience, and fifteen of the participants participated in focus group discussions to further explore themes that emerged from the journal and survey data. Data from the focus group and journals were analyzed qualitatively. The responses from the surveys provided quantitative data. In addition, the researchers looked at the Clinical Instructors (CI) midterm comments on the APTA's Clinical Performance Instrument (APTA PT CPI WEB) to further corroborate or disconfirm the findings. Results: Triangulation of the data points revealed 9 categories of positive impact that the pro bono experience had on their first full-time clinical experience. The strongest three categories in order were client interaction, clinical instructor interaction, and professional communication. The next five categories were of relative equal strength and related to specifics areas of competency. They were competency in documentation, evaluation, intervention, clinical reasoning, and cultural competency. A final overarching category was increased confidence. $\mathrm{Cl}$ comments on the midterm CPI corroborated these findings. Participants also shared ways in which the pro bono experience could have better prepared them for their full-time clinical experience. Conclusions: Regular participation in a pro bono clinic throughout the didactic portion of the physical therapy curriculum contributed to student confidence and competence in their first full-time clinical experience. Future research should include interviews with the clinical instructors to further corroborate the student perceptions. The findings of this study also serve to inform how the pro bono clinical experience can be enhanced to further contribute positively to the students' first fulltime clinical experience.
\end{abstract}

\section{INTRODUCTION}

Physical therapy programs strive to provide the best preparation possible for their students' full-time clinical experiences. To that end, programs explore effective ways to connect the classroom and laboratory to authentic clinical situations. The literature identifies various curricular models that seek to prepare students for real-world experiences such as problem-based learning and case-based education. ${ }^{1-5}$ High fidelity simulation laboratory experiences as well as incorporation of standardized patients to simulate client encounters are also evident in the literature. ${ }^{6-14}$ These various curricular strategies and pedagogical approaches strive to bring relevance and authenticity to the classroom, thus enhancing the student learning experience.

Service learning and community engagement activities offer a unique pedagogical approach that moves the learning out of the classroom into the community. Both activities have been shown to enhance student growth in a number of areas including 
professionalism, cultural competency and client-centered care, and clinical reasoning. ${ }^{15-22}$ Another example of extending student learning beyond the classroom is the integrated clinical education model. A number of programs have moved toward integrating the didactic portion of the curriculum with part-time, clinical experiences within local physical therapy clinics prior to sending students out on their full-time experiences. ${ }^{23-26}$ Others have established fully functioning clinics within their program and have their students participate in those experiences prior to their full-time experience off campus. ${ }^{27}$

These strategies all call upon students to be actively engaged in their learning process moving from a faculty-centered teaching paradigm toward a more student-centered learning paradigm as espoused by Barr and Tagg and Lave and Wenger. $28-29$ The student-centered learning paradigm calls for the faculty member to serve as facilitator and collaborator in student learning. ${ }^{28}$ Students have the responsibility of actively engaging and reflecting upon their learning in the context of the learning experience. ${ }^{30}$

The probono clinic provides a service-learning experience that incorporates a clinical practice experience within the community for their physical therapy students. ${ }^{31}$ At the pro bono clinic, students, under licensed supervision of faculty and community physical therapists, provide care for the uninsured or underinsured community members of Chester, Pennsylvania. A Student Board consisting of 12-14 students from each class are in charge of all administrative aspects of the clinic. Interested students apply for a position in the first semester of study. They begin service in their second semester of study and continue in their role until they depart for final clinical experiences in their last year of study. While the Student Board is responsible for the administrative leadership of the clinic, all DPT students are required to serve a minimum of three evenings/semester. This is a global requirement across the curriculum and has attachment to several classes throughout the three years of study. Students will have served for 4.5 semesters before going out on their first formal, full-time clinical education experience. The clinic is open all year with a two-week break in August and December. Service hours are from 4:00-7:00 pm Mondays, Tuesdays, Wednesdays, and Thursdays. Students provide direct physical therapy services in the clinic but under the licensed supervision of full-time faculty, adjunct faculty, and local area licensed physical therapists who volunteer their time with the clinic. This unique experience allows the students to transfer what they learn in the classroom to the evaluation and treatment of uninsured and underinsured patients in the community. Previous research on this particular project demonstrate that the students who serve on the administrative leadership board (Student Board) perceive an improvement in their clinical and administrative skills, an enhancement of their collaborative teamwork skills, and a stronger commitment to the community and the profession. ${ }^{32}$

The purpose of the study was to explore the influence that service in a physical therapy pro bono clinic has on a first full-time doctor of physical therapy clinical education experience.

\section{METHODOLOGY:}

\section{Design}

The study utilized mixed-methods using primarily a qualitative research design with an additional quantitative survey and review of the Cl's midterm Clinical Performance Instrument ${ }^{33}$ (APTA PT CPIWEB) comments to further corroborate or disconfirm the findings. Data collection methods included journals, focus groups, a Likert-scale electronic survey and analysis of clinical instructor comments on the participants' APTA PT CPIWEB at midterm.

\section{Participants}

The research participants were doctor of physical therapy (DPT) students in their third year of study in a private doctoral of physical therapy program about to enter their first full-time clinical education experience. The Widener University Institutional Review Board approved this study. Recruitment occurred in the Professional Seminar class, an ungraded weekly opportunity for the class to meet and have information communicated and presented as needed.

\section{Data Collection}

Each consenting participant kept a weekly journal throughout their 10-week, full-time clinical experience noting any influences that their experience in the pro bono clinic was having on their current experience. Each participant was to complete the journal entry according to the journal guide. Please see Appendix A. The journal guide included probes, some of which were informed by the previous findings of Black et al. ${ }^{32}$

After completion of the 10-week, full-time clinical experience and the submission of journals, three focus groups allowed for deeper exploration and clarity of responses from the journals. One focus group consisted of six participants, another five, and third one consisted of four. The focus groups averaged 50 minutes in length, were recorded, and transcribed verbatim. One researcher served as moderator of the sessions and another served as scribe. Focus group questions were broad and were based on themes and questions that arose from the journal analysis. The focus group questions are listed in Appendix B. The moderator did not take

(C) The Internet Journal of Allied Health Sciences and Practice, 2017 
part in the focus group discussion but rather waited until the group had exhausted their discussion of one question before posing the next question to the group.

Upon completion of the full-time clinical experience, all participants completed a survey of ten Likert-scale questions. The five-point Likert-scale ranged from "not at all" and "a high degree" as anchor descriptions for numbers 1 and 5 , respectively. Survey questions were developed prior to the start of the study and were based on the themes identified from an earlier qualitative investigation into student experiences in creating and launching the Chester Community Physical Therapy Clinic. ${ }^{32}$ Emergent themes from the previous study were thought to provide a relevant framework as they were pertinent to an earlier group of students who had experienced service in the same clinic. Survey questions were developed by one investigator and reviewed and refined by the other investigators. The survey items also served to inform some of the probes included in the journal guide. The survey was completed on hard copy and returned in an unmarked envelope to the primary researcher. The survey instrument is included in Appendix C.

Finally, to provide additional insights into student competence during the clinical experience from the perspective of the clinical instructor, one researcher who serves as Director of Clinical Education (DCE) reviewed the $\mathrm{Cl}$ midterm evaluation comments for each participant's APTA PT CPI WEB. Midterm performance was chosen versus the final performance, to better capture any influence of the prior pro bono experience. APTA PT CPI WEB ratings were not analyzed, as these are dependent on caseload, and may not truly reflect performance in a practice area. The APTA PT CPI WEB comments were used to corroborate or disconfirm findings from the student accounts in the journals and focus groups.

\section{Data Analysis}

Survey data were analyzed using SPSS version 20. Descriptive statistics including frequency, percentages, median, and range were calculated. Frequency counts for gender, role in the pro bono clinic, and full-time clinical setting were performed. Percentages for the Likert-scale items were calculated. The median and range for hours of pro bono clinic service hours also were calculated. The median was used as the data were bimodal. Data analysis of the APTA PT CPIWEB CI midterm comments was conducted by one researcher, the DCE.

Data analysis of the journals and the focus group transcripts were conducted in alignment with conventional content analysis ${ }^{34}$ Two of the researchers studied the journals and the focus group transcripts and individually generated a list of meaning units. The researchers then met to compare meaning units and began the process of category construction. A second revision considering the strength and frequencies of meaning units resulted in a revised category framework and mutually exclusive categories. In a third revision, categories were further refined, organized, and named to best capture the content of each of the nine emergent categories.

\section{Trustworthiness of Findings}

Trustworthiness and confirmability of the findings were enhanced by the triangulation of the qualitative data across the journals and the focus group transcripts as well as the corroboration or disconfirmation of the survey findings and APTA PT CPI WEB comments. The researchers kept an audit trail of the qualitative data analysis and attempted to practice comprehensive exposition in explanation of the methodology and data analysis. Member checking further enhanced trustworthiness and confirmability. The primary researcher sent the qualitative category construction out to all participants for input. Thirteen (81\%) of the participants responded and all were in agreement that the findings represented their experience. In reporting of participant voices, all participants are quoted at least once and no more than three times. Finally, the researchers practiced reflexivity by continually sharing biases and checking one another's assumptions. The primary researcher was a student in the class at the time. She shared in the experiences at the pro bono clinic as well as went out on her first clinical experience at the same time as her classmates. She conducted the participant recruitment session as part of the professional seminar. She also served as scribe in the focus groups. She brought a student lens to the analysis and had to balance the role of a researcher and a peer to the participants. The second researcher served as a faculty member and advisor to the pro bono clinic in the program. The third researcher was one of the Directors of Clinical Education in the program and had served as a supervisor in the pro bono clinic. She had extensive experience with the APTA PT CPI WEB instrument. The fourth researcher was also a faculty member and advisor to the pro bono clinic in the program. She had extensive experience with survey research. All four researchers had connections and experiences with the pro bono clinic from differing perspectives and each brought a unique lens and skillset to the research.

\section{RESULTS}

Thirty class members initially signed informed consent to participate in the study and received a guide for completing the journal reflections. Upon completion of the 10-week full-time clinical internship, 16 of the participants ( 3 males, 16 females) turned in a completed weekly journal. Fourteen of the initial participants did not submit a completed journal and dropped out of the study by

(C) The Internet Journal of Allied Health Sciences and Practice, 2017 
default. Fifteen of the sixteen participated in the focus groups. One participant opted out of the focus group. The researchers collected information on the participants' clinical settings, their role within the student-run physical therapy pro bono clinic, and the number of hours they served in the pro bono clinic prior to their first full-time clinical experience. Five students were student board members and 11 were student physical therapists in the pro bono clinic. The students' full-time clinical settings were as follows: 3 in inpatient rehab, 1 in an international clinical setting, 1 in a skilled nursing facility, 6 in outpatient, 4 in acute care and 1 in both an outpatient and acute care setting. The median number of hours served in the pro bono clinic was 90 (range 75-129).

\begin{tabular}{|l|l|l|l|c|}
\hline \multicolumn{9}{|c|}{ Table 1. Participant Demographics } \\
\hline 1 & Gender & Role in the Pro Bono Clinic & Full-Time Clinic Setting & $\begin{array}{c}\text { Number of Hours Served in } \\
\text { the Pro Bono Clinic (hours) }\end{array}$ \\
\hline 2 & Male & Student board member & Outpatient & 120 \\
\hline 3 & Female & Student physical therapist & Acute care & 75 \\
\hline 4 & Student physical therapist & Inpatient rehab & 75 \\
\hline 5 & Female & Student physical therapist & Inpatient rehab & 90 \\
\hline 6 & Female & Student board member & Acute care & 129 \\
\hline 7 & Female & Student board member & Outpatient & 102 \\
\hline 8 & Female & Student physical therapist & Ocute care & 123 \\
\hline 9 & Female & Student physical therapist & Outpatient & 75 \\
\hline 10 & Male & Student physical therapist & Acute care & 90 \\
\hline 11 & Female & Student physical therapist & Skilled nursing facility & 102 \\
\hline 12 & Female & Student physical therapist & Inpatient rehab & 75 \\
\hline 13 & Female & Student physical therapist & Outpatient & 90 \\
\hline 14 & Female & Student board member & Outpatient; Acute care & 90 \\
\hline 15 & Female & Student physical therapist & Outpatient & 117 \\
\hline 16 & Female & Student physical therapist & International clinical setting & 81 \\
\hline
\end{tabular}

Qualitative analysis of the journals and focus group transcripts revealed nine distinct categories in which the pro bono experience contributed favorably to the performance in their first full-time clinical experience. It also revealed a list of ways that the pro bono experience might be improved to better enhance the first full-time clinical experience.

The nine categories encompassing the benefits of participation in the pro bono clinic experience included in order of strength of data included the following: Client Interaction, Clinical Instructor Interaction, Professional Communication, Documentation, Competency in Examination, Competency in Interventions, Competency in Clinical Reasoning, and Competency in Cultural Encounters. An overall category of "Increased Confidence" emerged. All categories are depicted in Box 1. 


\section{Client Interaction}

\section{Box 1. Final Categories}

- conducting an interview

- educating clients and their families

- establishing rapport with clients

\section{Clinical Instructor Interaction}

- comfortable asking for and accepting feedback

- comfortable acting on feedback

- exhibiting initiative

\section{Professional Communication}

-presenting at Grand Rounds in an interprofessional setting -chart review

\section{Competency: Documentation}

- cohesive \& comprehensive assessments

- electronic medical Records

- documenting efficiently

\section{Competency: Examination}

- utilizing standardized tests

- sequencing of the exam

\section{Competency: Intervention}

- transfers and gait training

- therapeutic exercise

- hands-on skills (soft tissue / mobs)

\section{Competency: Clinical Reasoning or Emergency Situations}

- recognizing signs and symptoms

- vital signs - response to emergency situations

\section{Competency: Cultural Competency}

- working with diverse populations

- working with clients where English is a second language

Increased Confidence

\section{Client Interaction}

Strength of categories was determined by the frequency and emphasis of meaning units in a particular category when triangulated across all data points. The strongest category to emerge was client interaction. Participants reported feeling comfortable approaching clients, initiating client treatments, conversing throughout client evaluation and treatment, explaining treatments, and answering questions. For example, participants reported

I am surprised at how comfortable I am working with patients and simply interacting with them. I feel that the clinic has helped prepare me for working with patients in a real world setting. It's easy to keep a conversation going while figuring out exercises or examining a joint. -Participant 1

I find being empathetic with my patients and just simply listening to their stories has come easier to me because I have gotten that awkward first encounter with a patient over with last year at the pro bono clinic. -Participant 4

The qualitative findings in this category are corroborated by $\mathrm{Cl}$ comments on the APTA PT CPI WEB at midterm under the sections Communication and Educational Intervention. In the area of Communication, greater than $50 \%$ of the participants were described as "excellent" at midterm, with specific comments on student ability to engage with the patients. Documented behaviors included 
"listens effectively to the $\mathrm{Cl}$ and patient," able to "connect with the patient," "excellent communication skills," and "exceeds expectations for this level." The area of Educational Intervention revealed an array of comments at midterm, including "confident with patient education," "able to explain the role of PT well," "explanations to the patient are clear and include request for patient recall," and student ability to identify client barriers to learning.

Likewise the Likert-scale survey further corroborated the strength of the category with $93.8 \%$ of participants indicating that that the pro bono clinic experience positively impacted their abilities to interact with clients. Additionally, $81.3 \%$ indicated a positive impact on their ability to provide compassionate care.

\begin{tabular}{|c|c|c|c|c|c|}
\hline & $\begin{array}{c}1 \\
\text { Not at All } \\
\end{array}$ & 2 & 3 & 4 & $\begin{array}{c}5 \\
\text { High Degree } \\
\end{array}$ \\
\hline $\begin{array}{l}\text { 1. To what degree did your experience in the } \\
\text { pro bono clinic impact your performance in } \\
\text { your full-time clinical experience? }\end{array}$ & $0.0 \%$ & $0.0 \%$ & $25.0 \%$ & $62.5 \%$ & $12.5 \%$ \\
\hline $\begin{array}{l}\text { 2. To what degree did your experience in the } \\
\text { pro bono clinic impact your confidence in your } \\
\text { full-time clinical experience? }\end{array}$ & $0.0 \%$ & $0.0 \%$ & $6.3 \%$ & $50.0 \%$ & $43.8 \%$ \\
\hline $\begin{array}{l}\text { 3. To what degree did your experience in the } \\
\text { pro bono clinic impact your compassion in your } \\
\text { full-time clinical experience? }\end{array}$ & $0.0 \%$ & $0.0 \%$ & $18.8 \%$ & $56.3 \%$ & $25.0 \%$ \\
\hline $\begin{array}{l}\text { 4. To what degree did your experience in the } \\
\text { pro bono clinic impact your leadership ability in } \\
\text { your full-time clinical experience? }\end{array}$ & $0.0 \%$ & $6.3 \%$ & $43.8 \%$ & $18.8 \%$ & $31.3 \%$ \\
\hline $\begin{array}{l}\text { 5. To what degree did your experience in the } \\
\text { pro bono clinic impact your clinical competence } \\
\text { in your full-time clinical experience? }\end{array}$ & $0.0 \%$ & $0.0 \%$ & $18.8 \%$ & $75.0 \%$ & $6.3 \%$ \\
\hline $\begin{array}{l}\text { 6. To what degree did your experience in the } \\
\text { pro bono clinic impact your cultural } \\
\text { competence in your full-time clinical } \\
\text { experience? }\end{array}$ & $0.0 \%$ & $0.0 \%$ & $12.5 \%$ & $31.3 \%$ & $56.3 \%$ \\
\hline $\begin{array}{l}\text { 7. To what degree did your experience in the } \\
\text { pro bono clinic impact your professionalism in } \\
\text { your full-time clinical experience? }\end{array}$ & $0.0 \%$ & $0.0 \%$ & $6.3 \%$ & $50.0 \%$ & $43.8 \%$ \\
\hline $\begin{array}{l}\text { 8. To what degree did your experience in the } \\
\text { pro bono } \\
\text { clinic impact your relationship/interaction with } \\
\text { clients in your full-time clinical experience? }\end{array}$ & $0.0 \%$ & $0.0 \%$ & $6.3 \%$ & $37.5 \%$ & $56.3 \%$ \\
\hline $\begin{array}{l}\text { 9. To what degree did your experience in the } \\
\text { pro bono clinic impact your } \\
\text { relationship/interaction with clinical instructors } \\
\text { in your full-time clinical experience? }\end{array}$ & $0.0 \%$ & $6.3 \%$ & $12.5 \%$ & $62.5 \%$ & $18.8 \%$ \\
\hline $\begin{array}{l}\text { 10.To what degree did your experience in the } \\
\text { pro bono clinic impact your documentation } \\
\text { skills in your full-time clinical experience? }\end{array}$ & $0.0 \%$ & $12.5 \%$ & $6.3 \%$ & $43.8 \%$ & $37.5 \%$ \\
\hline
\end{tabular}

\section{Clinical Instructor Interaction}

$\mathrm{Cl}$ interaction was the second strongest category across the data. Participants reported comfort with accepting constructive criticism from Cls due to having received constructive criticism from supervisors and student members at the Clinic since the start of their physical therapy curriculum. Participants also recognized when to ask for feedback or help from a clinical instructor and feeling comfortable doing so because of relationships with supervisors at the Clinic.

Getting more comfortable when patients ask you questions. I feel like the first time it happened at the pro bono clinic, you're like oh my god I don't know. And then you might have to ask our supervising clinician but we feel comfortable if 
we don't know the answer, we feel comfortable either saying I don't know or saying well this person can answer it for you -Focus Group 1, Participant 1

I received positive comments that I was good at taking the feedback and I think that the pro bono clinic had something to do with that too because there we were always with the supervisors and as students we were always getting told you can do this better or here's a different way to do it, you missed this. -Focus Group 1, Participant 2

Already being involved with a licensed therapist who is practicing daily at the clinic made it simpler and made me feel more comfortable when interacting with my $\mathrm{Cl}$ to seek guidance, receive criticism, and so on. -Participant 5

These findings were corroborated by midterm $\mathrm{Cl}$ comments in the APTA PT CPI WEB. Specifically, in the area of Professional Behavior, $75 \%$ of the participants received comments at midterm noting their ability to accept and incorporate feedback well. Other comments included "takes initiative," "presents self in a professional manner," and "seeks feedback." Summative midterm comments included "beyond entry level," "ready to jump in," and "picks things up quickly."

The Likert-scale survey demonstrated that $81.3 \%$ of the participants felt that the pro bono clinic experience favorably impacted their ability to relate with their clinical instructor.

\section{Professional Communication}

In addition to reporting ease of communication with clients, family members, and clinical instructors, the data revealed an ease of communication in formal case round scenarios. Participants felt comfortable and confident communicating with other members of the health care team such as doctors, nurses, and social workers. They felt they communicated accurately and effectively within grand rounds or case meetings, asking and fielding questions necessary for optimal care of their patient. This also included conducting thorough and effective chart reviews.

I felt very comfortable during our team rounds today thanks to the experience of rounds that the pro bono clinic has given me. Basically, at rounds, the physicians, nurses, PTs, OTs, SLP, and the case manager go through one patient at a time and each comment on their assistance needed, their cognition, their speech, and the barriers that are limiting them from improvement at this time. I felt comfortable being able to comment on each patient, as we have been doing this for months now. - Participant 4

Doing chart reviews, because you're not constantly following that patient on a daily basis. So every time I was in the pro bono clinic I was looking at previous notes and assessments and plans and how they are going to do and kind of getting an idea of what to expect. I found myself doing that regularly at clinic from the first couple of days when I started - Focus Group 3; Participant 14

In the APTA PT CPI WEB areas of Communication and Professional Behaviors, Cls comment on the participants' abilities to seek out and accept feedback, exhibit engaged listening skills, and higher than expected ability to engage in professional dialogue, both in one-to-one and group settings. The Likert-scale survey indicated that $93.8 \%$ felt that the pro bono clinic experience positively influenced their development of professionalism (see Table 2).

The next five categories related to enhanced competency: competency in documentation, examination, intervention, clinical reasoning, and cultural competency and had relatively equal representation in the data but were not as strong as the first three categories.

\section{Competency: Documentation}

Documentation during clinical affiliations was a key aspect that participants reported was enhanced as a result of experiences at the pro bono clinic both in routine documentation of actual client care as well as documenting in an electronic medical record.

I feel sometimes actually documenting in class is different than documenting in a clinical setting so I think the fact that we have documented in a clinical setting just made it. Just being able to describe how someone actually reacted to therapy or responded to it was easier and I definitely got complimented on that. -Focus Group 1, Participant 4

I also had the opportunity to complete a lot of documentation this week and I felt comfortable with this from the experience of documenting a few evaluations and many daily notes in the pro bono clinic. -Participant 15 
It was easy for me to adapt to the documentation (EMR) system because I have been documenting in the clinic at school. It is not the same (EMR) system but I was able to quickly adjust because it was not my first time documenting. -Participant 11

In the APTA PT CPI WEB area of Documentation at midterm, Cls commented on the participant's ability to "quickly pick up the EMR system," "ability to link impairment to goals," "justify the intervention," "summarize information," and "write thorough, accurate, and concise notes". Summative comments included "an area of strength," "above expected level," and "strong documentation to justify PT service." In the Likert-scale survey, $81.3 \%$ of respondents indicated that the pro bono clinic experience enhanced their documentation skills (see Table 2).

\section{Competency: Examination}

Competency in examination is reflected in the following quotes.

On the first day of my clinical, I was thrown right into a patient interview, writing an assessment and gathering measurements. I was still extremely nervous but knowing I had done this same thing throughout my 2 years at our pro bono clinic made the process easier to handle. -Participant 13

One of my strengths was my evaluations. My $\mathrm{Cl}$ specifically mentioned that my sequencing and flow of my evaluations was strong and I never seemed like I didn't know what to do next. I attribute this to my experience evaluating real patients with real injuries at the pro bono clinic. -Participant 3

Working in the pro bono clinic has helped me feel more comfortable and confident in using evidence-based tools and standardized assessments in order to guide patient evaluations, interventions, and even discharge planning in my clinical experience. -Participant 12

In the APTA PT CPI WEB area of Examination at midterm, over 50\% of the Cls at midterm commented on the participants' thoroughness of the examination and medical interview. Positive comments describing the participants' solid examination skills were also noted. In the Likert-scale survey, $81.3 \%$ of respondents indicated that the pro bono clinic experience enhanced their clinical competence (see Table 2).

\section{Competency: Intervention}

Competency related to intervention emerged in many areas as depicted by the following quotes.

Where in class were working with each other and try to teach each other how to gait train or transfer but were all pretty mobile and functional so it was nicer to be in the clinic and actually work with patients who had these different disabilities and dysfunctions and that kind of carried over when I went to acute care and I had to do the same thing with my patients. -Focus Group 2, Participant 7

I have one patient here who has limited dexterity and fine motor skills in the left upper extremity. I have started doing handwriting skills with him, which I did a lot in the pro bono clinic on the mirror. Here we don't have a mirror to use but we do have pen and paper, which has been a great functional way to utilize intrinsic muscle strengthening. -Participant 16

I have had the opportunity to walk and transfer a max assist with a patient several times. $\mathrm{My} \mathrm{Cl}$ has given me the reigns to guard and she follows the patient with the wheelchair. In the pro bono clinic, I have had experience with assisting lower level patients with transfers and walking. I think a lot of that comfort with transferring the patient came from the experience in our clinic. -Participant 3

In the APTA PT CPI WEB area of Procedural Intervention at midterm, Cl's comments included "selects more beneficial procedures," "able to adjust intervention," "safe and competent with basic skills," and "resourceful." In the Likert-scale survey, $81.3 \%$ of respondents indicated that the pro bono clinic experience enhanced their clinical competence (see Table 2).

\section{Competency: Clinical Reasoning \& Emergency Situations}

Participants reported being able to treat patients easier because they had prior experiences with similar diagnoses, client presentations, plans of care, and/or emergent events at the clinic. Here are a few statements they made that demonstrated how 
the pro bono clinic experience allowed them to recognize patterns and enhanced their clinical reasoning skills, particularly in emergent situations.

And even though in the clinic we usually know who is going to be in, you don't know who for sure you will be working with until you get there and sometimes that patient doesn't show up and someone else does and then you will be working with them... I think that helps with being able to think on your feet... noticing something isn't working in the session and deciding that we aren't going to do that anymore and making the adjustment to something else. We get to do that in the pro bono clinic and I think it helps us. -Focus Group 1, Participant 5

Dealing with emergency events. Actually in the pro bono clinic I had a patient go orthostatic on me and we talked about it in class but it completely different when it actually happens in front of you and its pretty severe situation. And in the hospital that was pretty common, almost daily I would see things like that and I felt much more comfortable dealing with the patient when these kinds of things happened. I felt that I knew what I needed to do and what kind of action I needed to take. And I think if that hadn't happened to me in the pro bono clinic before my clinical I think I would have been a lot more nervous, fumbling, and afraid but I definitely had increased confidence again. -Focus Group 2, Participant 10

I was able to detect orthostatic hypotension and react quickly and appropriately. I was able to quickly take BP and HR due to the practice I gained in the pro bono clinic. -Participant 8

Comments provided by the $\mathrm{Cl}$ in the APTA PT CPI WEB in the area of Clinical Reasoning support students' basic skill in this area. Greater than $30 \%$ of the students received comments citing their ability to provide logical rationale for clinical decisions, use of literature to support an intervention, and a holistic approach to patient/client care.

\section{Competency: Cultural Competency}

The client encounters that the students experience at the pro bono clinic served to prepare them for diverse encounters in their full-time clinical experience. These included competence in navigating language barriers, different cultural health care beliefs and practices, and different family systems.

I have noticed that having a patient who has English as a secondary language at clinic prepared me for evaluating a Spanish-speaking patient this week. I didn't feel as uncomfortable as I would have been had I not had prior experience. -Participant 2

During my time at clinic, I have had several patients who do not speak English well other than a couple of phrases to convey pain. $\mathrm{My} \mathrm{Cl}$ has been impressed with my ability to work with these patients to convey what I want them to do through tactile cues or demonstration. This made me think back to the pro bono clinic because I have treated several patients who have either been non-English speaking or hard of English. -Participant 9

In the APTA PT CPI WEB area of Cultural Competence at midterm, two thirds of the study participants received midterm comments from their $\mathrm{Cl}$ reflection "strong competence" with qualifying descriptions like "takes patient needs into account," "adapts physical therapy appropriately," "handles interactions very well," and "good use of an interpreter." The Likert-scale survey indicates that $87.6 \%$ indicated a pro bono clinic positive influence on their cultural competency (see Table 2).

\section{Increased Confidence}

Overall, the participants reflected increased confidence moving into their first full-time clinical experience secondary to their experience in the pro bono clinic. The following quotes capture the overall impact that the pro bono clinic had on their preparedness for their first full-time clinic experience.

The entire experience in the pro bono clinic turned what other students may have as head knowledge into an understanding and a routine. -Participant 3

I think one of the biggest things for me was the familiarity with actually treating a patient that it wasn't the first time I was putting my hands on a patient when I walked into my clinical setting. -Focus Group 2, Participant 6

For me going into my first clinical, I wasn't even nervous about treating patients. It was more about what my $\mathrm{Cl}$ going to be like, how are we going to function together, and how is this going to work. I think that is from the pro bono clinic. We go in there and we learn people are going to present in different ways even if they have the same diagnosis. Just being

(C) The Internet Journal of Allied Health Sciences and Practice, 2017 
comfortable with the patient on that first day makes a world of difference and it's definitely because of the pro bono clinic experience. -Focus Group 3, Participant 12

Overall, in the APTA PT CPI WEB, Cls document confident performance for a first full-time clinical practice experience, as evidenced by summative APTA PT CPIWEB comments of "well prepared," "I would not have known this was a first full-time experience," and "excellent student." The Likert-scale survey indicated that $93.8 \%$ of the participants felt that the pro bono clinic experience enhanced their confidence (see Table 2).

\section{Participant Recommendations for Improvement}

Within the focus groups, participants offered suggestions for how the pro bono clinic experience might be improved to better prepare future students for their first full-time clinical experience. These areas included attention to time management, the overuse of flow charts, a lack of patient program progression, and a lack of practice delegating to PTAs or aides. In regards to time management, participants reported they would have liked better preparation and practice with efficiency in documentation and client care. This included having more experience documenting while treating a patient, or point/click service, managing more than one client during the same time period, and overall gaining more efficiency with client care. One participant noted the following:

One thing that sticks out to me is time management. In the clinic you might see one patient a night. When I was at clinical I was seeing 16 patients a day. So just the whole idea of time management with multiple patients and getting ready for the next patient while you're still with a patient.

Participants reported feeling restricted from the flow charts used at the pro bono clinic. Several participants felt that the flow charts did not encourage independent thinking when it comes to treatment programs. Since many of their clinical experiences did not have flow charts to reference prior to treating a patient, many felt challenged when required to create treatment programs for patients. They felt they did not gain a lot of experience with creating and updating patient goals that are individualized and realistic for each patient. One participant noted the following:

When I was at the [pro bono] clinic as a first-year or second-year student, I would just follow the flow sheet and sometimes I wouldn't even think of going off of that. When I was at [full-time] clinic, I would sit down with the flow sheet and my $\mathrm{Cl}$ would remind me that I don't need to do that and I can do whatever I want, progress them or do something different and switch it up. I think at the clinic were stuck at this concrete flow sheet and people are scared to differ from it.

Experience with delegating client care to PTAs and aides was lacking. One participant stated, "Probably the area that I had to work on most was assigning tasks and duties to a PTA, stuff for them to do or how to help you because we don't do that at all at the pro bono clinic." At the pro bono clinic, these types of personnel are not available for use; therefore, students are unable to gain this type of exposure and experience, but they might be able to practice delegating to one another. Lastly, participants reported they would have benefited greatly from more experience with doing initial evaluations with patients. Some participants reported they had some experience and wished they had more and others reported they did not have or did not take the opportunity to do an initial evaluation at the pro bono clinic but wish now that they had.

\section{DISCUSSION AND CONCLUSIONS}

The categories of client interaction, clinical instructor interaction, and professional communication emerged with greatest strength and representation across the data points. Documentation and four specific areas of competency development in examination, intervention, clinical reasoning, and cultural competence also emerged but to a lesser degree. Increased confidence described the overall benefit to the participant, and the focus group responses helped to delineate areas in which the pro bono clinic experience might be improved to further prepare future students for their first full-time clinical experience.

The findings of this study resonate with the work of Lindquist, Engardt, and Richardson who sought to understand what learning experiences physiotherapy students perceived to be most meaningful. ${ }^{35}$ They found that the students most valued learning from participation in a clinical context. Students in the Institute for Physical Therapy Education begin learning from participation in a clinical context in their very first semester of the physical therapy program and their participation and involvement at the pro bono clinic increases over time. Lindquist's research also found that students value learning from self and others. The "others" in their research study included teachers, clinical tutors, peers, and patients. The Chester Community Physical Therapy Clinic affords students the opportunity to learn from faculty, clinical supervisors, more experienced student, and the patients. Finally, students in Lindquist's study also noted the importance of learning from support and feedback of teachers and clinical tutors. The students in our study also highlighted the value of having had positive interactions, support, and feedback with clinical mentors at the Chester

(C) The Internet Journal of Allied Health Sciences and Practice, 2017 
Community Physical Therapy Clinic, and that this facilitated the transition to interacting with their clinical instructor in their first formal clinical experience. Lindquist's findings correlate with the two strongest categories of this study.

Interprofessional communication emerged as a strength of the pro bono clinic experience. This is not unusual as the literature describes a number of pro bono clinic models where multiple disciplines work in collaboration with one another and interprofessional collaboration is enhanced. ${ }^{36-38}$ However, at the time of the study, the University did not collaborate with disciplines other than physical therapy. While chart reviews can be considered a component of examination, the authors made the decision to include this in professional communication because the students were reflecting upon their clinic experience of "Grand Rounds" when they were referring to their increased comfort with interprofessional communication. Grand Rounds is a course that is offered in conjunction with service in the University. A team consisting of first, second, and third year physical therapy students meet every three weeks to discuss the client cases on their team. The students deliver the case presentations to one another and an adjunct faculty member facilitates the discussion. They acknowledged this experience as their preparation for case communications in their formal clinical settings.

The development of clinical reasoning skills in a student pro bono clinic experience is also not new in the literature. Seif et al distributed a clinical reasoning survey to a cohort of students who participated in a pro bono clinic and a matching cohort who did not. ${ }^{21}$ Students in the experimental group showed a statistically significant improvement in their perception of their clinical reasoning skills after participating in the pro bono service clinic. This coincides with the findings of Black, Palombaro, and Dole where students who participated in a student-run pro bono clinic felt they had enhanced their clinical skills. ${ }^{32}$ The findings around cultural competency are not surprising either and are corroborated by a number of articles in the service-learning literature that demonstrate that students working with clients of different cultures in authentic contexts helps them develop cultural understandings and competencies. ${ }^{16-18}$

The items that the participants identified as lacking in their experience are useful in considering how the pro bono experience might be enhanced. Clinical supervisors could challenge students with time management skills and the more experienced students could be asked to take on more than one client at a time and practice delegating to first and second-year students. With the addition of Grand Rounds, the students should move away from reliance on a flow chart and instead focus on client progression of goals and program based on sound clinical reasoning. As for opportunities to perform evaluations and re-evaluations, to date it has been up to the student to offer to take those on, but the program could easily mandate that every student take a turn. The suggestions that arose from study participants will be very useful in further shaping the student learning experience in preparation for their first fulltime clinical education experience.

True to the nature of qualitative research, this study can only be generalized to other programs that provide their students with a service learning experience in a clinical type setting, such as a pro bono physical therapy clinic. It is our hope that we have provided enough detail such that readers may be able to find some relevance and applicability to their specific situations. As noted previously, all four researchers had experience and various roles within the pro bono clinic. This creates a potential bias in analyzing the findings. In particular, the primary researcher had to juxtapose the role of researcher with that of student and peer. At the same time, all four researchers brought different lens and skills to the research and worked to challenge one another's assumptions and biases. Additionally, while the themes from a previous study provided a preliminary framework for the development of the Likertsurvey, it would have been valuable to have conducted an initial analysis of the emergent themes from the journals and allowed those themes to frame the Likert-study. For example, the themes "performance" and "leadership" were not something that emerged in the journal or focus group data. Likewise, the themes of "clinical competency" actually emerged as examination, intervention, and clinical reasoning in the current study. The timing of survey development and IRB approval prohibited the development of the survey after initial analysis. In the future, it would be beneficial to alter the timing of the survey development to allow the data analysis of the journals to inform the survey questions. Finally, the data reflects the student participant perspectives with a limited input from clinical instructors via their ratings and comments on the CPIWEB at midterm. Future research might be conducted to specifically interview or survey the clinical instructors to capture their perspective more comprehensively.

Regular participation in a pro bono clinic throughout the didactic portion of the physical therapy curriculum contributed to student confidence and competence in the areas of client interaction, clinical instructor interaction, professional communication, documentation, examination, intervention, clinical reasoning, and cultural competency. Findings were corroborated by clinical instructor APTA PT CPI WEB midterm comments. Future study should further explore the perspective of the clinical instructors. The findings of this study also serve to inform how the pro bono clinic experience can be enhanced to further contribute positively to the students' first full-time clinic experiences.

(C) The Internet Journal of Allied Health Sciences and Practice, 2017 


\section{References}

1. Gunn H, Hunter H, Haas B. Problem-based learning in physiotherapy education: A practice perspective. Physiother. 2012;98(4):335-40. doi: 10.1016/j.physio.2011.05.005. [PMID: 23122440]

2. Jefferson JR. Problem-based learning and the promotion of problem solving: Choices for physical therapy curricula. $J$ Phys Ther Educ. 2001;15(1):26-31.

3. Suzuki S, Maruyama H. Influence of PBL (problem-based learning) tutorial on practical training of PT students. $J$ Phys Ther Sci. 2010;22(1):81-6. doi: 10.1589/jpts.22.81

4. Tichen AC, Coles CR. Comparative study of physiotherapy students' approaches to their study in subject-centered and problem-based curricula. Physiother Theory Prac. 1991;7(2):127-33. doi: 10.3109/09593989109106963

5. van Duijn AJ, Bevins SI. Clinical Performances of Physical Therapist Students in Problem-Based, Mixed-Model, and Traditional Curricula. J Phys Ther Educ. 2005;19(2):15-21.

6. Ohtake PJ, Lazarus M, Schillo R, Rosen M. Simulation Experience Enhances Physical Therapist Student Confidence in Managing a Patient in the Critical Care Environment. Phys Ther. 2013;93(2):216-28. doi: 10.2522/ptj.20110463. [PMID: 23329555]

7. 7.Mori B, Carnahan $\mathrm{H}$, Herold J. Use of simulation learning experiences in physical therapy entry-to-practice curricula: a systematic review. Physiother Canada. 2015;67(2):194-202. doi: 10.3138/ptc.2014-40E. [PMID: 25931672]

8. Smith N, Prybylo S, Conner-Kerr T. Using simulation and patient role play to teach electrocardiographic rhythms to physical therapy students. Cardiopulm Phys Ther J. 2012;23(1):36-42. [PMID: 22807654]

9. Lefebvre KM, Wellmon R, Ferry D. Changes in attitudes toward interprofessional learning and collaboration among physical therapy students following a patient code simulation scenario. Cardiopulm Phys Ther J. 2015;26(1):8-14.

10. Shoemaker MJ, Riemersa L, Perkins R. Use of high fidelity human simulation to teach physical therapist decision-making skills for the intensive care setting. Cardiopulm Phys Ther J. 2009;20(1):13-9. [PMID: 20467529]

11. Hayward L, Blackmer B, Markowski A. Standardized patients and communities of practice: A realistic strategy for integrating the core values in a physical therapist education program. J Phys Ther Educ. 2006;20(2):29-34.

12. Paparell-Pitzel $S$, Edmond $S$, DeCaro $C$. The use of standardized patients in physical therapy education programs. $J$ Phys Ther Educ. 2009;23(2):15-23.

13. Hale LS, Lewis DK, Eckert RM, Wilson CM, Smith BS. Standardized patients and multidisciplinary classroom instruction for physical therapist students to improve interviewing skills and attitudes about diabetes. J Phys Ther Educ. 2008;20(1):22-7.

14. Panzarella KJ, Manyon AT. Using the integrated standardized patient examination to assess clinical competence in physical therapist students. J Phys Ther Educ. 2008;22(3):24-32.

15. Crandell C ,WiegandM, Brosky Jr. J. Examining the Role of Service-Learning on Development of Professionalism in Doctor of Physical Therapy Students: A Case Report. J Allied Health. 2013;42(1):25-32. [PMID: 23471290]

16. Wise HH, Yuen HK. Effect of Community-Based Service Learning on Professionalism in Student Physical Therapists. J Phys Ther Educ. 2013;27(2):58-64.

17. Furze J, Black L, Peck K, Jensen GM. Student perceptions of a community engagement experience: Exploration of reflections on social responsibility and professional formation. Physiother Theory Prac. 2011;27(6):411-21. doi: 10.3109/09593985.2010.516479. PMID: 20946070

18. Hayward L, Charette AL. Integrating cultural competence and core values: An international service learning model. J Phys Ther Educ. 2012;26(1):78-89.

19. Mercer VS, Zimmerman MY, Schrodt LA, Palmer VE, Samuels V. Interprofessional education in a rural community-based falls prevention project: The CHAMP experience. J Phys Ther Educ. 2014;28(2):35-45.

20. Roskell C, White D, Bonner C, Fairchild R. Developing patient-centered care in health professionals and reflections on introducing service-learning into the curriculum. Int J Therapy Rehab. 2012;19(8):448-57. doi: 10.12968/ijtr.2012.19.8.448

21. Seif G, Coker-Bolt P, Kraft S, Gonsalves W, Simpson K, Johnson E. The development of clinical reasoning and interprofessional behaviors: service-learning at a student-run free clinic. J Interprof Care. 2014; 28(6):559-64. doi: 10.3109/13561820.2014.921899. [PMID: 24865993]

22. NowakowskiK, Kaufman R, PelletierD. A Clinical Service Learning Program Promotes Mastery of Essential Competencies in Geriatric Physical Therapy. J Phys Ther Educ. 2014;28(2):46-53.

23. Weddle ML, Sellheim DO. Linking the Classroom and the Clinic: A model of integrated clinical education for first-year physical therapist students. J Phys Ther Educ. 2011;25(3):68-79.

24. Mai JA, Stern DF, Hollman JH, Melzer B, Thiele AK, Rosenthal RS. Examining the impact of an integrated clinical experience (ICE) on interpersonal skills prior to the first, full-time clinical internship: Cool as ICE. J Phys Ther Educ. 2014;28(3):81-97.

25. Mai JA, Thiele A, O'Dell B, Kruse B, Vaasen M, Priest A. Utilization of an integrated clinical experience in a physical therapist education program. J Phys Ther Educ. 2013;27(2):25-32.

26. Weddle ML, Sellheim DO. An integrative curriculum model preparing physical therapists for Vision 2020 practice. J Phys Ther Educ. 2009;23(1):12-21.

(C) The Internet Journal of Allied Health Sciences and Practice, 2017 
27. Wilson AM. Integrated clinical experiences in a campus onsite clinic: A self-contained model of physical therapy clinical education. Internet J Allied Health Sci Pract. 2014;12(3):1-17.

28. Barr RB, Tagg J. From teaching to learning: A new paradigm for undergraduate education. Change. 1995;27(6):13-25.

29. Lave J, Wenger E. Situated Learning: Legitimate Peripheral Participation. 1991. Cambridge, MA: Cambridge University Press.

30. Schon D. The Reflective Practitioner: How professionals think in action. 1983. Boston, MA: Basic Books.

31. Palombaro KM, Dole RL, Black Lattanzi, J. A case report of a student-led pro bono clinic: a proposed model for meeting student and community needs in a sustainable manner. Phys Ther. 2011:91(11);1627-35. [PMID: 21868614]

32. Black JD, Palombaro KM, Dole RD. Student experiences in creating and launching a student-led physical therapy pro bono clinic: a qualitative investigation. Phys Ther. 2013;93(5):637-48. [PMID: 23431216]

33. American Physical Therapy Association. Physical Therapist Clinical Performance Instrument for Students: APTA; 2006. Retrieved at: https://cpi2.amsapps.com/docs/PT_final_revision_11-30-2010.pdf. Accesed September 1, 2016.

34. Hsieh HF, Shannon SE. Three approaches to qualitative content analysis. Qual Health Res. 2005;15:1277-88.

35. Lindquist I, Engardt M, Richardson B. Early learning experiences valued by physiotherapy students. Learn Health Soc Care. 2004;3(1):17-25.

36. Moskowitz D, Glasco J, Johnson B, Wang G. Students in the community: an interprofessional student-run free clinic. J Interprof Care. 2006; 20(3):254-9. [PMID: 16777793]

37. Wang T, Bhakta H. A new model for interprofessional collaboration at a student-run free clinic. J Interprof Care. 2013; 27:33940. doi: 10.3109/13561820.2012.761598. [PMID: 23368712]

38. Farlow J, Goodwin C, Sevilla J. Interprofessional education through service-learning: lessons from a student-led free clinic. $J$ Interprof Care. 2015; 29(3):263-4.doi: 10.3109/13561820.2014.936372. [PMID: 25565371] 